\title{
Rapid Static Sensitizer Regeneration Enabled by Ion Pairing
}

\author{
Laura Casarin, ${ }^{\dagger}$ Wesley B. Swords, ${ }^{\ddagger}$ Stefano Caramori, ${ }^{\dagger}$ Carlo A. Bignozzi, ${ }^{* \dagger}$ and Gerald J. Meyer* ${ }^{*}+0$ \\ ${ }^{\dagger}$ Department of Chemistry and Pharmaceutical Sciences, University of Ferrara, Via Fossato di Mortara 17, 44121 Ferrara, Italy \\ ${ }^{\ddagger}$ Department of Chemistry, The University of North Carolina at Chapel Hill, Murray Hall 2202B, Chapel Hill, North Carolina \\ 27599-3290, United States
}

Supporting Information

ABSTRACT: An anionic $\mathrm{Co}^{\mathrm{II}}$ complex, $[\mathrm{Co}(\mathrm{TTT})$ $\left.(\mathrm{NCS})_{3}\right]^{-}\left(\mathrm{TTT}=4,4^{\prime}, 4^{\prime \prime}\right.$-tri-tert-butyl-2,2' $: 6^{\prime}, 2^{\prime \prime}$-terpyridine and NCS = isothiocyanate), was synthesized for use in dye-sensitized solar cells (DSSCs). The Co ${ }^{\mathrm{II}}$ complex was found to ion-pair with the hexacationic sensitizer $\left[\mathrm{Ru}(\mathrm{tmam})_{2}(\mathrm{dcb})\right]^{6+}\left(\mathrm{tmam}=4,4^{\prime}\right.$ - bis (trimethylaminomethyl)-2,2'-bipyridine and $\mathrm{dcb}=4,4^{\prime}$ $\left(\mathrm{CO}_{2} \mathrm{H}\right)_{2}-2,2^{\prime}$-bipyridine) anchored to $\mathrm{TiO}_{2}$ thin films immersed in acetonitrile solution. Visible light excitation of the ion pairs resulted in excited-state injection followed by rapid static regeneration of the oxidized sensitizer $(<10$ ns). The static component to regeneration gave an ion-pair equilibrium constant of $6000 \mathrm{M}^{-1}$. This value is an order of magnitude smaller than the equilibrium constant determined for $\left[\mathrm{Ru}(\mathrm{tmam})_{2}(\text { deeb })\right]^{6+}\left(\right.$ deeb $=4,4^{\prime}$ $\left(\mathrm{CO}_{2} \mathrm{Et}\right)_{2}-2,2^{\prime}$-bipyridine) dissolved in acetonitrile. DSSC studies employing $\left[\mathrm{Co}(\mathrm{TTT})(\mathrm{NCS})_{3}\right]^{-}$or the cationic $\left[\mathrm{Co}(\mathrm{DTB})_{3}\right]^{2+}\left(\mathrm{DTB}=4,4^{\prime}\right.$-di-tert-butyl-2,2'-bipyridine $)$ as redox mediators revealed a 3 fold photocurrent increase in the presence of the anionic cobalt complex. As the regeneration step was greatly enhanced through the formation of Coulombic ion pairs, both electron injection and regeneration were complete within $10 \mathrm{~ns}$ which is unprecedented for dye-sensitization. The results obtained reveal that ground-state ion-pairing can be a powerful strategy for DSSC optimization.

$\mathrm{D}$ etrimental to the efficiency of dye-sensitized solar cells (DSSCs) is interfacial electron transfer from the semiconductor to the oxidized sensitizer (back electron transfer) or redox mediator. ${ }^{1-3}$ The observation of nearly quantitative absorbed photon-to-electron conversion values led many to believe that the former reaction was not relevant to an optimized DSSC. ${ }^{4,5}$ Every excited sensitizer molecule that injected an electron into the semiconductor was believed to be quantitatively regenerated by the reduced redox mediator (donor), typically iodide or a cobalt diimine complex. This is indeed the case for optimized DSSCs measured at the short-circuit condition. However, recent studies have shown that at maximum power conversion efficiency (i.e., the power point), back electron transfer to the oxidized sensitizer represents a significant loss mechanism. ${ }^{6,7}$ In other words, regeneration of the oxidized sensitizer is not quantitative when power is extracted. This back electron transfer is also problematic in unoptimized DSSCs that employ viscous solvents, ${ }^{8,9}$ irradiances greater than one sun, or redox mediators with poor solubility such as many cobalt complexes. $^{10-12}$

Here, we present ground-state ion-pairing as a new strategy to maintain a high concentration of redox mediators at the dyesensitized interface. A novel anionic $\mathrm{Co}^{\mathrm{II}}$ complex was synthesized and characterized for this purpose. When utilized with a hexacationic sensitizer, compelling experimental evidence for ion-pairing was observed that enabled rapid (<10 ns) "static" sensitizer regeneration without the need for mediator diffusion. In comparative studies, such rapid regeneration resulted in improved DSSC performance.

The investigated sensitizers and redox mediators with their abbreviations are shown in Scheme 1 . Closely related $\mathrm{Ru}$

\section{Scheme 1. Sensitizers and Redox Mediators}
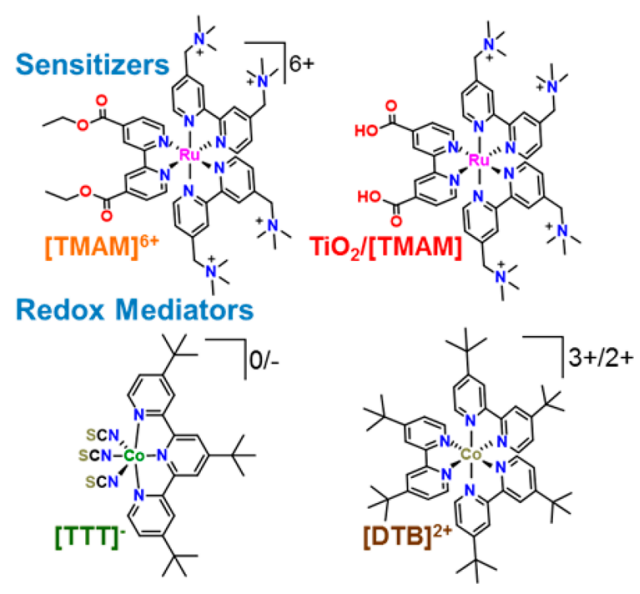

compounds bearing the dicationic tmam ligand were previously reported. ${ }^{13}$ The ethyl ester derivative was used here for solution studies, with the carboxylic acid form used for anchoring to mesoporous thin films of anatase $\mathrm{TiO}_{2}$ nanocrystallites common to DSSCs. The tert-butyl substituted terpyridine in [TTT $]^{-}$was employed to inhibit close contact with the $\mathrm{TiO}_{2}$ surface. ${ }^{12}$ The three isothiocyanate ligands render the complex anionic in the $\mathrm{Co}^{\mathrm{II}}$ oxidation state and neutral when oxidized to $\mathrm{Co}^{\mathrm{III}}$. For comparison, the well-known $[\mathrm{DTB}]^{2+}$ and $\mathrm{I}^{-} / \mathrm{I}_{3}^{-}$redox mediators were also utilized. ${ }^{11,14,15}$

The electronic absorption spectra of $\left[\mathrm{TMAM}^{6+}\right.$ and $[\mathrm{TTT}]^{-}$ complexes in acetonitrile are shown in Figure S1. As with

Received: April 16, 2017 

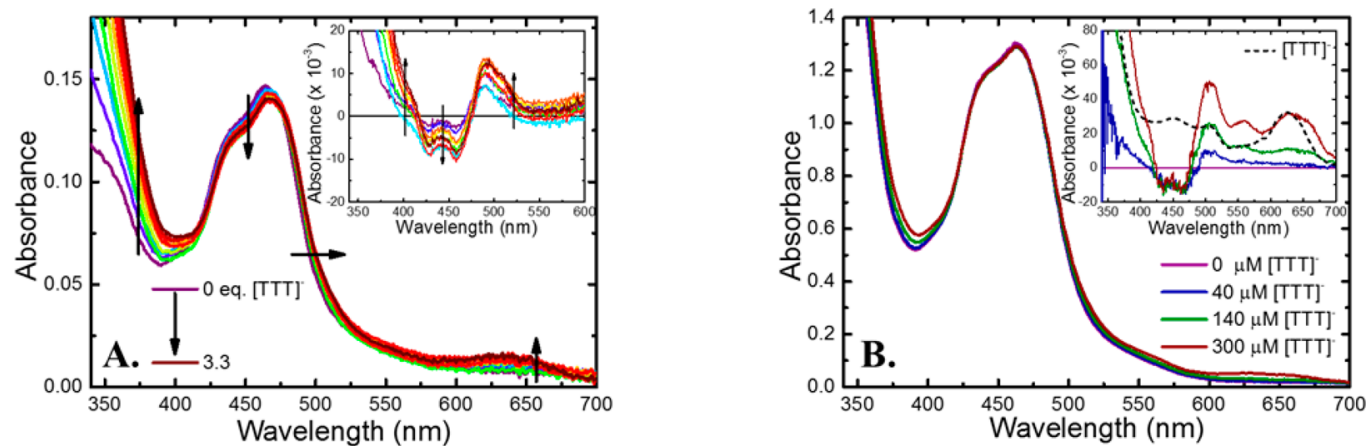

Figure 1. (A) Visible absorption spectra of $[\mathrm{TMAM}]^{6+}\left(9 \mu \mathrm{M}\right.$ in $\left.\mathrm{CH}_{3} \mathrm{CN}\right)$ with up to 3.3 equiv of [TTT $]^{-}$. The absorbance increase at $630 \mathrm{~nm}$ was due to $[\mathrm{TTT}]^{-}$. Inset: difference spectra indicate a MLCT red shift and decrease below $410 \mathrm{~nm}$. (B) Visible absorption spectra of $\mathrm{TiO}_{2} / \mathrm{TMAM}$ in $100 \mathrm{mM}$ $\mathrm{LiClO}_{4} / \mathrm{CH}_{3} \mathrm{CN}$ with added $[\mathrm{TTT}]^{-}$. Inset: difference spectra with overlaid $[\mathrm{TTT}]^{-}$spectrum.

Table 1. Solution Excited-State Quenching Constants and Solar Device Properties

\begin{tabular}{|c|c|c|c|c|c|c|c|}
\hline mediator & $K_{\mathrm{S}}\left(\times 10^{4} \mathrm{M}^{-1}\right)$ & $K_{\mathrm{D}}\left(\times 10^{4} \mathrm{M}^{-1}\right)$ & $k_{\mathrm{q}}\left(\times 10^{9} \mathrm{M}^{-1} \mathrm{~s}^{-1}\right)$ & $J_{\mathrm{SC}}\left(\times 10^{-3} \mathrm{~A} \mathrm{~cm}^{-2}\right)$ & $V_{\mathrm{OC}}(\mathrm{V})$ & FF & $\eta(\%)$ \\
\hline$[\mathrm{TTT}]^{-}$ & $8.6 \pm 0.3$ & $1.3 \pm 0.1$ & $6.0 \pm 0.5$ & $1.19 \pm 0.10$ & $0.33 \pm 0.02$ & $0.49 \pm 0.05$ & $0.21 \pm 0.02$ \\
\hline$[\mathrm{DTB}]^{2+}$ & $a$ & $a$ & $a$ & $0.48 \pm 0.10$ & $0.52 \pm 0.02$ & $0.44 \pm 0.09$ & $0.11 \pm 0.02$ \\
\hline $\mathrm{I}^{-}$ & $2.0 \pm 0.1$ & $b$ & $b$ & $1.48 \pm 0.10$ & $0.47 \pm 0.01$ & $0.62 \pm 0.04$ & $0.45 \pm 0.03$ \\
\hline
\end{tabular}

${ }^{a}$ No photoluminescence quenching was evident. ${ }^{b}$ Due to a nonlinear nature, the dynamic quenching for iodide is not reported.

$[\mathrm{DTB}]^{2+}$, $[\mathrm{TTT}]^{-}$displayed ligand localized transitions in the $\mathrm{UV}$ region as well as a weak visible absorption out to $700 \mathrm{~nm}$. The visible absorption spectrum of $[\text { TMAM }]^{6+}$ displayed intense bands in the 400-500 $\mathrm{nm}$ region that were typical of metal-toligand charge transfer (MLCT) excited-state transitions. Light excitation into the MLCT absorption bands led to room temperature photoluminescence (PL).

The addition of $[\mathrm{TTT}]^{-}$to a $[\mathrm{TMAM}]^{6+}$ acetonitrile solution resulted in significant changes in the MLCT absorption band, with a shift to longer wavelengths and concurrent intensity decrease that saturated at 3.3 equiv. These spectral changes were consistent with ion pairing, which is most easily identified by the difference spectra, Figure 1A inset. ${ }^{13,16,17}$

The PL intensity and lifetime of photoexcited [TMAM] ${ }^{6+}$ decreased with the addition of [TTT $]^{-}$, Figure S2. In the absence of $[\mathrm{TTT}]^{-}$, the $[\mathrm{TMAM}]^{6+}$ MLCT excited-state relaxed with first-order kinetics and a lifetime, $\tau_{\mathrm{o}}=2.1 \mu \mathrm{s}$. Upon [TTT $]^{-}$ addition, the initial PL amplitude decreased significantly, indicative of static quenching, ${ }^{18}$ while the excited-state lifetime decreased slightly. Both the changes in lifetime and PL amplitude were analyzed through the Stern-Volmer model. ${ }^{18}$ An ion-pair equilibrium constant, $K_{\mathrm{eq}}$, of $86000 \pm 3000 \mathrm{M}^{-1}$ was estimated from a linear approximation to the data. A linear fit was not entirely successful, presumably due to the presence of multiple ion-paired species. A dynamic quenching rate constant $\left(k_{\mathrm{q}}\right)$ of $(6.0 \pm 0.5) \times 10^{9} \mathrm{M}^{-1} \mathrm{~s}^{-1}$ was also extracted from the data. We note that the combination of static and dynamic quenching would be expected to give nonlinear Stern-Volmer plots had the steady state PL intensity been monitored.

Excited-state quenching experiments were also performed with $[\mathrm{DTB}]^{2+}$ and iodide, Table 1 . There was no evidence for ion-pairing or even a diffusional interaction between the two cationic species $[\mathrm{TMAM}]^{6+}$ and $[\mathrm{DTB}]^{2+}$, Figure S3. With iodide, both dynamic and static quenching processes were observed, and an equilibrium binding constant of $20000 \pm 1000$ $\mathrm{M}^{-1}$ was estimated, Figure S4. This was $\sim 4$ times smaller than that obtained with $[\mathrm{TTT}]^{-}$. The smaller equilibrium constant for iodide is not easily reconciled as iodide has a higher charge density. Perhaps there exists a specific interaction between
$[\mathrm{TTT}]^{-}$and $[\mathrm{TMAM}]^{6+}$. Overall, $[\mathrm{TTT}]^{-}$showed 4 times more static excited-state quenching than the other mediators studied.

Swapping the ethyl ester groups of $[\text { TMAM }]^{6+}$ for carboxylic acid groups allowed the compound to be anchored to the surface of mesoporous $\mathrm{TiO}_{2}$ thin films, abbreviated $\mathrm{TiO}_{2} / \mathrm{TMAM}$. The MLCT absorption spectrum was similar to that measured in neat acetonitrile, Figure $1 \mathrm{~B}$. The addition of $[\mathrm{TTT}]^{-}$to the $100 \mathrm{mM}$ $\mathrm{LiClO}_{4} / \mathrm{CH}_{3} \mathrm{CN}$ solution surrounding the sensitized thin film gave rise to changes in the MLCT absorption similar to those observed with the sensitizer in solution. The $\mathrm{TiO}_{2} / \mathrm{TMAM}$ spectral changes associated with ion-pairing were evident at 40 $\mu \mathrm{M}[\mathrm{TTT}]^{-}$concentrations. At even higher concentrations, ionpairing was more evident, and the $[\mathrm{TTT}]^{-}$absorbance also appeared, Figure 1B inset. Hence, all the spectral signatures associated with ion-pairing in $[\mathrm{TMAM}]^{6+}$ were observed for $\mathrm{TiO}_{2} /$ TMAM.

Pulsed light excitation of $\mathrm{TiO}_{2} / \mathrm{TMAM}$ in $100 \mathrm{mM} \mathrm{LiClO}_{4} /$ $\mathrm{CH}_{3} \mathrm{CN}$ solution resulted in absorption spectra consistent with an interfacial charge separated state consisting of an injected electron and oxidized sensitizer molecule, $\mathrm{TiO}_{2}\left(\mathrm{e}^{-}\right) /[\mathrm{TMAM}]^{+}$, Figure S5. ${ }^{2}$ The formation of this charge separated state could not be time-resolved, consistent with instrument response time limited excited-state injection, $k_{\text {inj }}>10^{8} \mathrm{~s}^{-1}$. Back electron transfer to form ground-state products was monitored at $405 \mathrm{~nm}$, which represents a ground-state/excited-state isosbestic point and was modeled by the Kohlrausch-Williams-Watts function. ${ }^{6,19,20}$ An average rate constant, $k_{\text {bet }}$ of $(3.6 \pm 0.5) \times 10^{3} \mathrm{~s}^{-1}$ was extracted. Interestingly, this rate constant did not change appreciably upon [TTT] ${ }^{-}$addition, but the initial amplitude did, Figure 2. A Stern-Volmer-type analysis of the initial amplitudes was linear and yielded an ion-pair equilibrium constant of $6000 \pm$ $300 \mathrm{M}^{-1}$. At the $80 \mathrm{mM}$ [TTT] ${ }^{-}$concentrations used for DSSC studies, the ground state bleach at $460 \mathrm{~nm}$ was no longer present, indicating that both excited-state injection and regeneration of $\mathrm{TiO}_{2}\left(\mathrm{e}^{-}\right) /[\mathrm{TMAM}]^{+}$were complete within 10 ns, i.e., $k_{\text {inj }}, k_{\text {reg }}>$ $10^{8} \mathrm{~s}^{-1}$, Figure S6. These data indicate a static regeneration mechanism that does not involve mediator diffusion. To our knowledge, such rapid regeneration in $\mathrm{CH}_{3} \mathrm{CN}$ is unprecedented. 


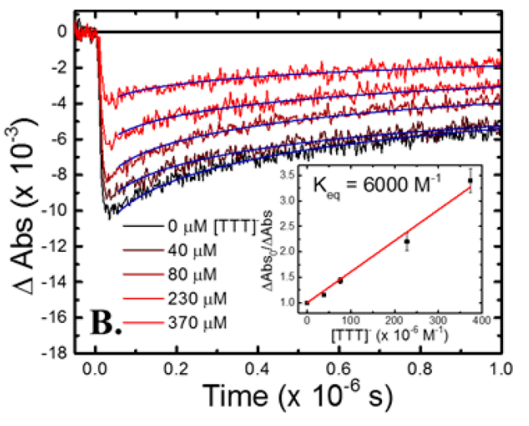

Figure 2. Absorption change monitored at $405 \mathrm{~nm}$ at the indicated $[\mathrm{TTT}]^{-}$concentrations. The inset shows a Stern-Volmer-type analysis of the initial amplitude change, attributed to static regeneration at time zero.

The improved electron-transfer kinetics from [TTT $]^{-}$ionpairing were validated by photoelectrochemical studies of DSSCs based on $\mathrm{TiO}_{2} /[$ TMAM] A 10:1 molar ratio of the reduced to oxidized [TTT $]^{-}$was employed, with $100 \mathrm{mM} \mathrm{LiTf}$, where Tf is trifluoromethanesulfonate. Dimethylformamide was added to $\mathrm{CH}_{3} \mathrm{CN}$ in a 1:3 ratio to enhance [TTT] ${ }^{-}$solubility. Shown in Figure 3 are photocurrent action spectra, the incident photon-tocurrent efficiency (IPCE) expressed as a percentage.

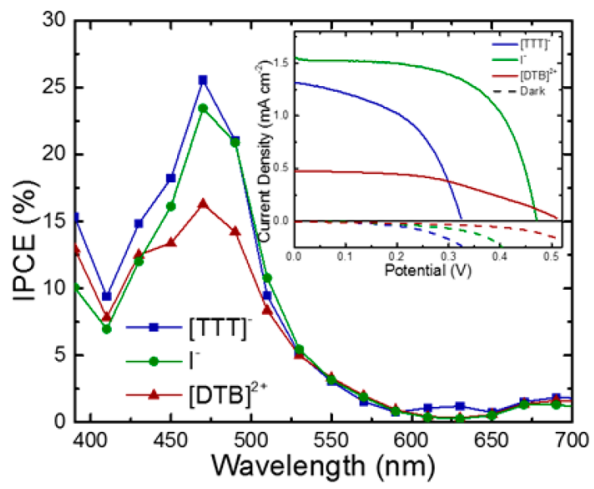

Figure 3. Photocurrent action spectra and JV curves in light (solid) and dark (dashed) with $[\mathrm{TTT}]^{-},[\mathrm{DTB}]^{2+}$, and $\mathrm{I}^{-} / \mathrm{I}_{3}^{-}$mediators and the $\mathrm{TiO}_{2} /[$ TMAM $]$ sensitizer.

Such photocurrent action spectra closely resembled the $\mathrm{TiO}_{2} /$ [TMAM] absorptance spectrum, consistent with a dye-sensitized photocurrent mechanism. The maximum IPCE measured for [TTT $]^{-}$based DSSCs was $26 \%$ with an absorbance of 0.42 , which corresponded to an absorbed photon-to-current efficiency of $41 \%$. For comparison, photocurrent action spectra with $[\mathrm{DTB}]^{2+}$ were recorded under identical conditions. The maximum IPCE was reduced to $16 \%$. A $0.7 \mathrm{M}$ iodide with 0.02 $\mathrm{M} \mathrm{I}_{2} \mathrm{CH}_{3} \mathrm{CN}$ electrolyte was also employed, yielding an IPCE of $23 \%$. Overall, $[\mathrm{TTT}]^{-}$and iodide produced similar photocurrent yields.

In addition, current-voltage (JV) curves were measured under 1 sun of AM 1.5 illumination, Figure 3 inset. The short circuit current measured with $[\mathrm{TTT}]^{-}$was $\sim 3$ times larger than that for $[\mathrm{DTB}]^{2+}$, indicating that the photocurrent efficiency for $[\mathrm{TTT}]^{-}$ was even larger than $[\mathrm{DTB}]^{2+}$ at higher illumination intensities. The $[\mathrm{TTT}]^{-}$performance was quite comparable to that measured for the typical iodide redox mediators, even with an iodide concentration almost 9 times greater than $[\mathrm{TTT}]^{-}$. We note that the iodide electrolyte contained additives known to enhance DSSC efficiency. ${ }^{21}$

The open circuit photovoltage $\left(V_{\mathrm{OC}}\right)$ of $0.33 \mathrm{~V}$ for the [TTT ${ }^{-}$ electrolyte was smaller than the $0.52 \mathrm{~V}$ value measured with $[\mathrm{DTB}]^{2+}$. Cyclic voltammetry revealed a quasi-reversible $\mathrm{Co}^{\mathrm{III} / \mathrm{II}}$ wave for [TTT $]^{-}$at $0.27 \mathrm{~V}$ vs NHE, which compares to $0.37 \mathrm{~V}$ for $[\mathrm{DTB}]^{2+}$, Figure $\mathrm{S} 8$. Hence, $100 \mathrm{mV}$ of the smaller $V_{\mathrm{OC}}$ can be rationalized based on the dark equilibrium potentials of the redox mediator, which is expected to reflect the Fermi energy of the PEDOT counter electrode. Indeed, the dark JV data revealed a more positive onset of the recombination current for $[\mathrm{TTT}]^{-}$ relative to $[\mathrm{DTB}]^{2+}$. The remaining $100 \mathrm{mV}$ loss cannot be accounted for by the equilibrium potentials and most likely reflects enhanced charge recombination to the redox mediator. The $t$-butyl groups in $[\mathrm{DTB}]^{2+}$ provided steric hindrance for a close approach to $\mathrm{TiO}_{2}{ }^{11,22}$ but the three isothiocyanate groups in $[\mathrm{TTT}]^{-}$may allow close approach and faster recombination.

Mass transport limitations due to the relatively low concentrations of the oxidized mediator were ruled out through the study of DSSCs prepared with the more conventional Z907, ${ }^{1}$ Figure S7. The Z907 complex, which is anionic before and after injection into $\mathrm{TiO}_{2}$ displayed the highest efficiency with $[\mathrm{DTB}]^{2+}$ followed by $[\mathrm{TTT}]^{-}$. Under these conditions, $[\mathrm{DTB}]^{2+}$ showed reasonable efficiencies, and the enhanced short circuit current with a loss of $V_{\mathrm{OC}}$ observed with $\mathrm{TiO}_{2} /[\mathrm{TMAM}]$ was therefore attributed to static regeneration and recombination as was described above.

Ion pairing offers the chance to lower the donor concentrations in the electrolyte, as ion-pairing increases the redox mediator concentration at the sensitized interface. When static regeneration is operative, smaller donor concentrations can be utilized to increase the open circuit voltage through a positive Nernstian shift of the redox mediator potentials. In the case of iodide based redox mediators, iodide and triiodide are both anionic and would both ion-pair with the sensitizer. ${ }^{13,16,17,23}$ An advantage of [TTT $]^{-}$is that it is neutral in its oxidized form with no Coulombic incentive to form ion pairs. Indeed, redox mediators that are charged in one oxidation state and neutral in the other, like [TTT $]^{-}$, offer ostensive advantages in DSSC design. This holds true for cases such as halogen bonding, which has previously been reported as a strategy for maintaining high interfacial mediator concentrations. ${ }^{24,25}$ However, the Coulombic effects discovered herein are of a much greater magnitude.

In conclusion, the novel anionic cobalt based redox mediator $[\mathrm{TTT}]^{-}$undergoes rapid static (i.e., nondiffusional) regeneration of the cationic [TMAM] sensitizer. The ground-state ionpair interaction between the two species was identified both in solution and at the nanocrystalline $\mathrm{TiO}_{2}$ interface. Static regeneration was observed at redox mediator concentrations well below those used for standard DSSCs. In comparative studies the anionic cobalt mediator displayed a significantly larger photocurrent than did standard cationic mediators. The extension of this work to "champion" sensitizers that more efficiently absorb sunlight is of great interest for future research.

\section{ASSOCIATED CONTENT}

\section{S Supporting Information}

The Supporting Information is available free of charge on the ACS Publications website at DOI: 10.1021/acs.inorgchem.7b00819.

Synthesis and experimental procedures (PDF) 


\section{AUTHOR INFORMATION}

\section{Corresponding Authors}

*E-mail: g4s@unife.it.

*E-mail:: gjmeyer@email.unc.edu.

\section{ORCID $\odot$}

Gerald J. Meyer: 0000-0002-4227-6393

\section{Notes}

The authors declare no competing financial interest.

\section{ACKNOWLEDGMENTS}

UNC authors acknowledge support from the National Science Foundation (NSF), award CHE-1213357, and the NSF Graduate Research Fellowship Program, DGE-1144081 (W.B.S). PRIN 2010-2011 is gratefully acknowledged for funding of the UF authors. HRMS was performed by the UNC Department of Chemistry Mass Spectrometry Core Laboratory.

\section{REFERENCES}

(1) Hagfeldt, A.; Boschloo, G.; Sun, L.; Kloo, L.; Pettersson, H. DyeSensitized Solar Cells. Chem. Rev. 2010, 110 (11), 6595-6663.

(2) Ardo, S.; Meyer, G. J. Photodriven Heterogeneous Charge Transfer with Transition-Metal Compounds Anchored to $\mathrm{TiO}_{2}$ Semiconductor Surfaces. Chem. Soc. Rev. 2009, 38 (1), 115-164.

(3) Nasr, C.; Hotchandani, S.; Kamat, P. V. Role of Iodide in Photoelectrochemical Solar Cells. Electron Transfer between Iodide Ions and Ruthenium Polypyridyl Complex Anchored on Nanocrystalline $\mathrm{SiO}_{2}$ and $\mathrm{SnO}_{2}$ Films. J. Phys. Chem. B 1998, 102 (25), 4944-4951.

(4) Hagfeldt, A.; Graetzel, M. Light-Induced Redox Reactions in Nanocrystalline Systems. Chem. Rev. 1995, 95 (1), 49-68.

(5) Haque, S. A.; Tachibana, Y.; Willis, R. L.; Moser, J. E.; Grätzel, M.; Klug, D. R.; Durrant, J. R. Parameters Influencing Charge Recombination Kinetics in Dye-Sensitized Nanocrystalline Titanium Dioxide Films. J. Phys. Chem. B 2000, 104 (3), 538-547.

(6) Robson, K. C. D.; Hu, K.; Meyer, G. J.; Berlinguette, C. P. Atomic Level Resolution of Dye Regeneration in the Dye-Sensitized Solar Cell. J. Am. Chem. Soc. 2013, 135 (5), 1961-1971.

(7) Li, F.; Jennings, J. R.; Wang, Q. Determination of Sensitizer Regeneration Efficiency in Dye-Sensitized Solar Cells. ACS Nano 2013, 7 (9), 8233-8242.

(8) Fabregat-Santiago, F.; Bisquert, J.; Palomares, E.; Otero, L.; Kuang, D.; Zakeeruddin, S. M.; Grätzel, M. Correlation between Photovoltaic Performance and Impedance Spectroscopy of Dye-Sensitized Solar Cells Based on Ionic Liquids. J. Phys. Chem. C 2007, 111 (17), 65506560 .

(9) Wang, P.; Wenger, B.; Humphry-Baker, R.; Moser, J.-E.; Teuscher, J.; Kantlehner, W.; Mezger, J.; Stoyanov, E. V.; Zakeeruddin, S. M.; Grätzel, M. Charge Separation and Efficient Light Energy Conversion in Sensitized Mesoscopic Solar Cells Based on Binary Ionic Liquids. J. Am. Chem. Soc. 2005, 127 (18), 6850-6856.

(10) Wu, J.; Lan, Z.; Lin, J.; Huang, M.; Huang, Y.; Fan, L.; Luo, G. Electrolytes in Dye-Sensitized Solar Cells. Chem. Rev. 2015, 115 (5), 2136-2173.

(11) Hamann, T. W. The End of Iodide? Cobalt Complex Redox Shuttles in DSSCs. Dalt. Trans. 2012, 41 (11), 3111.

(12) Gibson, E. A.; Smeigh, A. L.; Le Pleux, L.; Hammarström, L.; Odobel, F.; Boschloo, G.; Hagfeldt, A. Cobalt Polypyridyl-Based Electrolytes for P-Type Dye-Sensitized Solar Cells. J. Phys. Chem. C 2011, 115 (19), 9772-9779.

(13) Swords, W. B.; Li, G.; Meyer, G. J. Iodide Ion Pairing with Highly Charged Ruthenium Polypyridyl Cations in $\mathrm{CH}_{3} \mathrm{CN}$. Inorg. Chem. 2015, 54 (9), 4512-4519.

(14) Boschloo, G.; Hagfeldt, A. Characteristics of the Iodide/Triiodide Redox Mediator in Dye-Sensitized Solar Cells. Acc. Chem. Res. 2009, 42 (11), 1819-1826.

(15) Sapp, S. A.; Elliott, C. M.; Contado, C.; Caramori, S.; Bignozzi, C. A. Substituted Polypyridine Complexes of Cobalt(II/III) as Efficient
Electron-Transfer Mediators in Dye-Sensitized Solar Cells. J. Am. Chem. Soc. 2002, 124 (37), 11215-11222.

(16) Clark, C. C.; Marton, A.; Meyer, G. J. Evidence for Static Quenching of MLCT Excited States by Iodide. Inorg. Chem. 2005, 44 (10), 3383-3385.

(17) Marton, A.; Clark, C. C.; Srinivasan, R.; Freundlich, R. E.; Narducci-Sarjeant, A. A.; Meyer, G. J. Static and Dynamic Quenching of $\mathrm{Ru}(\mathrm{II})$ Polypyridyl Excited States by Iodide. Inorg. Chem. 2006, 45 (1), 362-369.

(18) Lakowicz, J. R. Principles of Fluorescence Spectroscopy, 3rd ed.; Lakowicz, J. R., Ed.; Springer US: Boston, MA, 2006.

(19) Williams, G.; Watts, D. C. Non-Symmetrical Dielectric Relaxation Behaviour Arising from a Simple Empirical Decay Function. Trans. Faraday Soc. 1970, 66 (1), 80.

(20) Lindsey, C. P.; Patterson, G. D. Detailed Comparison of the Williams-Watts and Cole-Davidson Functions. J. Chem. Phys. 1980, 73 (7), 3348-3357.

(21) Boschloo, G.; Häggman, L.; Hagfeldt, A. Quantification of the Effect of 4- Tert -Butylpyridine Addition to $\mathrm{I}^{-} / \mathrm{I}_{3}{ }^{-}$Redox Electrolytes in Dye-Sensitized Nanostructured $\mathrm{TiO}_{2}$ Solar Cells. J. Phys. Chem. B 2006, 110 (26), 13144-13150.

(22) Gaddie, R. S.; Moss, C. B.; Elliott, C. M. Cyclic Voltammetric Study of Cobalt Poly-4-t-Butylpyridine Ligand Complexes on Glassy Carbon Electrodes: Electrolyte Dependence and Mechanistic Considerations. Langmuir 2013, 29 (2), 825-831.

(23) Clark, C. C.; Marton, A.; Srinivasan, R.; Narducci Sarjeant, A. a.; Meyer, G. J. Triiodide Quenching of Ruthenium MLCT Excited State in Solution and on $\mathrm{TiO}_{2}$ Surfaces: An Alternate Pathway for Charge Recombination. Inorg. Chem. 2006, 45 (12), 4728-4734.

(24) Swords, W. B.; Simon, S. J. C.; Parlane, F. G. L.; Dean, R. K.; Kellett, C. W.; Hu, K.; Meyer, G. J.; Berlinguette, C. P. Evidence for Interfacial Halogen Bonding. Angew. Chem., Int. Ed. 2016, 55 (20), $5956-5960$

(25) Simon, S. J. C.; Parlane, F. G. L.; Swords, W. B.; Kellett, C. W.; Du, C.; Lam, B.; Dean, R. K.; Hu, K.; Meyer, G. J.; Berlinguette, C. P. Halogen Bonding Promotes Higher Dye-Sensitized Solar Cell Photovoltages. J. Am. Chem. Soc. 2016, 138 (33), 10406-10409. 